\title{
O CARNAVAL DE OLIVEIRA/ MG E SUA INTERPRETAÇÃO SOB A ÓTICA DA RESSIGNIFICAÇÃO DAS ESPACIALIDADES FESTIVAS
}

\author{
Matheus Resende TEIXEIRA ${ }^{1}$ \\ José Antônio Souza de DEUS²
}

\begin{abstract}
Resumo
Coloca-se em pauta neste artigo a perda de público dos carnavais interioranos de Minas Gerais a qual acreditamos que ocorra, enquanto o carnaval de Belo Horizonte recebe mais turistas. Para desenvolver a investigação, adotou-se uma atitude fenomenológica e os seguintes procedimentos: pesquisa bibliográfica e entrevistas semi-estruturadas analisadas qualitativamente. Explicitou-se aí que uma cidade festeira como Oliveira, tenta se adaptar às transformações em curso relacionadas a influências vindas de fora que se avolumam. Oliveira, sede de uma festa carnavalesca com características peculiares, é assim o recorte territorial da pesquisa que busca compreender como as espacialidades festivas podem se ressignificar. Conclui-se que é possível se observar uma excepcionalidade da sucessão de transformações experienciadas por este lugarfestivo, movimento que deve ocorrer também nas cidades carnavalescas do interior mineiro numa disputa intensa, entre si, pela hegemonia como lugares festivos atrativos para os visitantes e numa atmosfera de símbolos que se adensa durante a festividade.
\end{abstract}

Palavras-chave: Geografia Cultural. Espacialidades festivas. Lugar festivo. Carnaval. Carnavais tradicionais.

\section{OLIVEIRA/MG CARNIVAL AND ITS INTERPRETATION FROM THE PERSPECTIVE OF RE-SIGNIFYING FESTIVE SPATIALITIES}

\begin{abstract}
The loss of public in Carnival festivities in Minas Gerais state hinterland is at issue in this paper, that this reduction in Carnival participants occurs in towns located in this territorial context, we believe, while Carnival in Belo Horizonte receives increasingly tourists' contingents. A phenomenological attitude was adopted to carry out the research and bibliographic research and conducting semi-structured interviews (analyzed qualitatively), were adopted as methodological tools. A festivities city like Oliveira tries to adapt to the transformations in progress. Oliveira, home of a Carnival celebration with peculiar characteristics, is the territorial focus of the research that seeks to understand how festive spatialities can be re-signified. We concluded that it is possible to observe an exceptionality of transformations experienced by

\footnotetext{
${ }^{1}$ Graduando em Geografia - Instituto de Geociências/ UFMG. mresendeteixeira@hotmail.com

2 Prof. Associado IV- Programa de Pós-Graduação em Geografia- Instituto de Geociências/ UFMG. E-mail: jantoniosdeus@uol.com.br
} 
Oliveira's festive place, a movement that probably should occur in Carnival cities of Minas Gerais, in an intense dispute among themselves for the hegemony as the most attractive places for visitors and in an atmosphere of symbols that thickens during the festivity period.

Keywords: Cultural Geography. Festive spatialities. Festive place. Carnival. Traditional carnivals.

\section{EL CARNAVAL DE OLIVEIRA/MG Y SU INTERPRETACIÓN DESDE EL PUNTO DE VISTA DE LA RESIGNIFICACIÓN DE LAS ESPACIALIDADES FESTIVAS}

\section{Resumen}

Este artículo se centra en la pérdida de público de los carnavales del interior de Minas Gerais que creemos que se produce, mientras que el carnaval de Belo Horizonte recibe más turistas. Para desarrollar la investigación se adoptó una actitud fenomenológica y se utilizaron como procedimientos: investigación bibliográfica y entrevistas semiestructuradas, analizadas cualitativamente. Se explicó allí que una ciudad de fiesta como Oliveira intenta adaptarse a las transformaciones relacionadas con las influencias externas que están creciendo. Oliveira, sede de una fiesta de carnaval con características peculiares, es por lo tanto el recorte territorial de la investigación que busca comprender cómo pueden resignificar las espacialidades festivas. Se concluye que es posible observar una excepcionalidad de la sucesión de transformaciones experimentadas por el lugar festivo de Oliveira, movimiento que debería producirse en las ciudades de carnaval del interior de Minas Gerais, en una intensa disputa entre ellas por la hegemonía como los lugares festivos más atractivos, en una atmósfera de símbolos que se va espesando durante la fiesta.

Palabras-clave: Geografía Cultural. Espacialidades festivas. Lugar festivo. Carnaval. Carnavales tradicionales.

\section{INTRODUÇÃO}

O Carnaval é a festa popular brasileira mais conhecida internacionalmente. Em 2018, “400 mil estrangeiros [eram] esperados para curtir a folia no país” (G1, 2018), havendo então, a expectativa de injeção de $\mathrm{R} \$$ 11,4 bilhões na economia e mostrando-se a realização do evento fundamental ao planejamento econômico de muitas cidades foliãs. Pode-se afirmar que as noites de folia tidas como absolutamente integradas à cultura nacional, permeiam o imaginário como uma "válvula de escape" para as tensões do cotidiano, permitida, controlada e estimulada pelos grupos dominantes (DA MATTA, 
1981), para uma população que enfrenta cotidianamente uma diversidade de problemas.

$\mathrm{Na}$ festa ocorre, de qualquer forma, um adensamento das vivências que aglutinam as pessoas e comunidades envolvidas. Elas acabam assim sendo incorporadas ao imaginário coletivo das comunidades onde elas se desenvolvem (DEUS et al., 2016).

Embora não tenhamos dados que possam confirmar tal afirmação, parece-nos evidente, pela nossa própria vivência espacial e pela enorme repercussão que passaram a ter tais eventos na mídia, que na cidade de Belo Horizonte, capital de Minas Gerais, aumenta a cada ano o número de participantes e de investimentos da Prefeitura Municipal destinados às comemorações carnavalescas. Entretanto, como cidadãos locais que vivenciamos o cotidiano de uma pequena cidade do interior mineiro, observarmos empiricamente uma tendência contrária nas comemorações tradicionais, que,pelo menos em Oliveira/ MG (embora acreditemos que, também noutras cidades com perfil similar isso também se configure),ano após ano, vêm sendo reduzidas e fragilizadas, tanto em número de foliões que delas participam quanto ao que concerne ao investimento público, entre outros indicadores, como o tamanho dos blocos. Além disso, recorrentemente, a data festiva tem sido cancelada nessas localidades, por inúmeros motivos (MATIAS, 2019). E paralelamente a isso acreditamos que tem havido, nas festas interioranas (tal como vivenciamos em Oliveira), uma intensa desvalorização das figuras, personagens, símbolos e costumes típicos do lugar, dando-se mais espaço, aí, progressivamente, a elementos de culturas exógenas. Postulamos que, em muitos casos, isso possa se traduzir na fragilização das tradições locais, que vão sendo substituídas, cada vez mais, por simbologias externas voltadas essencialmente para o consumo, o que acaba por aumentar significativamente o grau de mercantilização da festividade.E é nessa perspectiva que Deus et al. (2016), se remetem a processos de ressignificação através dos quais os eventos festivos atualmente se transformam em objeto de consumo. 
A cidade de Oliveira 3 é uma das tantas que passa por problemas no que concerne à celebração do seu carnaval, e por termos uma relação existencial ligada a ela a selecionamos como área-foco de investigação. Por isso, no presente artigo, pretende-se, através da análise dos resultados de entrevistas semi-estruturadas realizadas com cinco cidadãos locais selecionados como interlocutores, devido ao seu íntimo relacionamento com a festa (em nossa apreciação, como moradores locais, há anos envolvidos com a questão), construir-se uma biografia espacial desse lugar festivo4, evidenciando as principais características e as mudanças pelas quais sua festa tem passado. Além disso, buscou-se bases teóricas 5 que ajudassem a explicar o que ocorre nesse movimento. E procurou-se, em paralelo, identificar como a revitalização do carnaval de rua de Belo Horizonte pode ter contribuído para que determinadas transformações ocorressem no Carnaval do hinterland mineiro e como a relação entre os dois recortes territoriais foi sendo modificada nesse processo. É relevante assinalar que decidimos analisar tais recortes em função de constituírem lugares em que o Carnaval tem aparentemente passado por grandes e recentes transformações, ainda que em sentidos díspares como problematizaremos adiante.

Empreendendo-se, na essência, uma investigação fundamentada em categorias de análise nítida e explicitamente geográficas geográficos (o lugar festivo, a vivência espacial, a espacialidade festiva)pretendeu-se, dessa maneira, trabalhar duas dimensões: uma local, na qual procurou se identificar características, peculiaridades e mudanças exclusivas da realidade concernente ao carnaval de Oliveira; e uma mais geral, propondo uma abordagem de um

\footnotetext{
3Cujas características essenciais apresentamos em etapa posterior deste trabalho.

4 Remetemo-nos aqui a uma "biografia espacial", tal qual ela é concebida pelo geógrafo Patrício Sousa, ao desenvolver uma dissertação de Mestrado que trabalhou a questão da Corporeidade para estudar grupos de Congado mineiros (em trabalho orientado pelo Prof. José Antônio S. Deus, no Programa de Pós-Graduação em Geografia- IGC/ UFMG). As pesquisas de campo foram desenvolvidas no Vale do Jequitinhonha, em Minas Novas/ MG (SOUZA, 2011).

5Apropriadas de pesquisa bibliográfica concernente a conceitos e temas relacionados à Geografia Cultural, Geografia das Representações, Espacialidades Festivas, etc. No campo da Geografia Cultural e Percepção Ambiental podemos destacar as contribuições trazidas de Tuan (2011), Kozel (2018), Almeida (2006), Deus et al. (2016) e Dias Neto \& Deus (2020). E vale ressaltar que, no caso das obras dos pesquisadores brasileiros, trata-se de produção intelectual de docentes vinculados à UFMG, UFPR, UFG e UFS, dedicados a investigações de cunho fenomenológico e etnográfico, nos últimos anos, em seus respectivos grupos de pesquisa, na pós-graduação em Geografia.
} 
movimento universal de mudanças que têm ocorrido nos carnavais interioranos mineiros. Não se observou, no entanto, uma cisão entre essas duas dimensões, tendo sido elas trabalhadas em conjunto, de forma dialógica e interligada. Observe-se que se pode remeter aqui também, a duas escalas de conceituação e análise do problema.

Buscou-se ainda, no trabalho, se efetuar uma contextualização e sistematização dos dados (primários e secundários) obtidos e proceder-se a uma reflexão crítica sobre os conceitos e temas investigados. Em termos das categorias geográficas contempladas, privilegiou-se, sobretudo, a análise do Lugar festivo, levando-se em consideração particularmente que, como aponta Kozel (2018, p. 07), parcelas determinadas do Espaço podem tornar-se "mais e mais familiares, incorporadas que são ao nosso íntimo, tornando-se lugares”.

\section{O CARNAVAL E A DISPUTA DE SIGNIFICADOSNOS LUGARES FESTIVOS}

A princípio, é preciso pensar sobre o papel e a origem da festividade carnavalesca(mundialmente conhecida e praticada) e correspondendo a um período anual de festas profanas (pagãs) que tiveram origem na Antiguidade e foram assimiladas e ressignificadas pelo Cristianismo, passando a se constituírem como festejos populares marcados pela informalidade e incontinência (DA MATTA, 1981), liberdade de expressão e movimento. Para isso, pode se pensar a festa enquanto um momento de adensamento das trocas simbólicas no Espaço, que é inundado por alegria, diversas emoções e confrontações, além de ser permeado por uma complexa disputa pelo lugar onde isso se concretiza (FERREIRA, 2003).

Ademais, é compreensível que, ao longo do tempo, a festa e o lugar onde ela se realiza passem por inúmeras transformações. Portanto, caso sofram interferências externas, é possível que tais eventos mantenham, somente em determinada medida, sua essência festiva nos moldes originais, singulares em cada lugar onde ela se desenvolve.

Ao se regatar a origem do Carnaval, verifica-se que, embora no Brasil a festividade seja amplamente identificada no imaginário popular como uma festa 
tipicamente nacional,registra-se na literatura que sua gênese remonta à Europa medieval, como uma comemoração católica que antecedia o período de penitência da quaresma (figura 1); e na qual se prezava principalmente o consumo de carne e álcool, antes do período de abstinência que se aproximava,imposto pela liturgia (DA MATTA, 1981).No entanto, pode-se perceber certa peculiaridade na versão brasileira da festa que, de certa forma, se apropria da festa europeia-tendo como agentes dessa apropriação, principalmente os negros e pobres-; tendo sido também, a festividade, aqui recontextualizada ("tropicalizada") e, nesse processo,transformada na comemoração símbolo da identidade nacional. Segundo Germano (1999, p. 143), no século XX:

No plano cultural, o popular, [o Carnaval] tornou-se sinónimo de nacionalidade, para onde a intelectualidade voltou suas atenções nos anos 30 e 40, redescobrindo o Brasil e redefinindo a identidade nacional brasileira. Desta forma, o carnaval popular foi apropriado no Brasil como festa nacional, em que o negro, o branco e o índio, estavam presentes no mito fundador da identidade nacional brasileira.

E nesse contexto é que também se torna possível, que se passasse a considerá-lo parte da essência nacional, transformando-se tal festa, a partir daí, no que se convencionou considerar-se parte integrante do ethos do povo brasileiro. 
Figura 1 -"A luta entre o Carnaval e a Quaresma", de Pieter Bruegel, o Velho

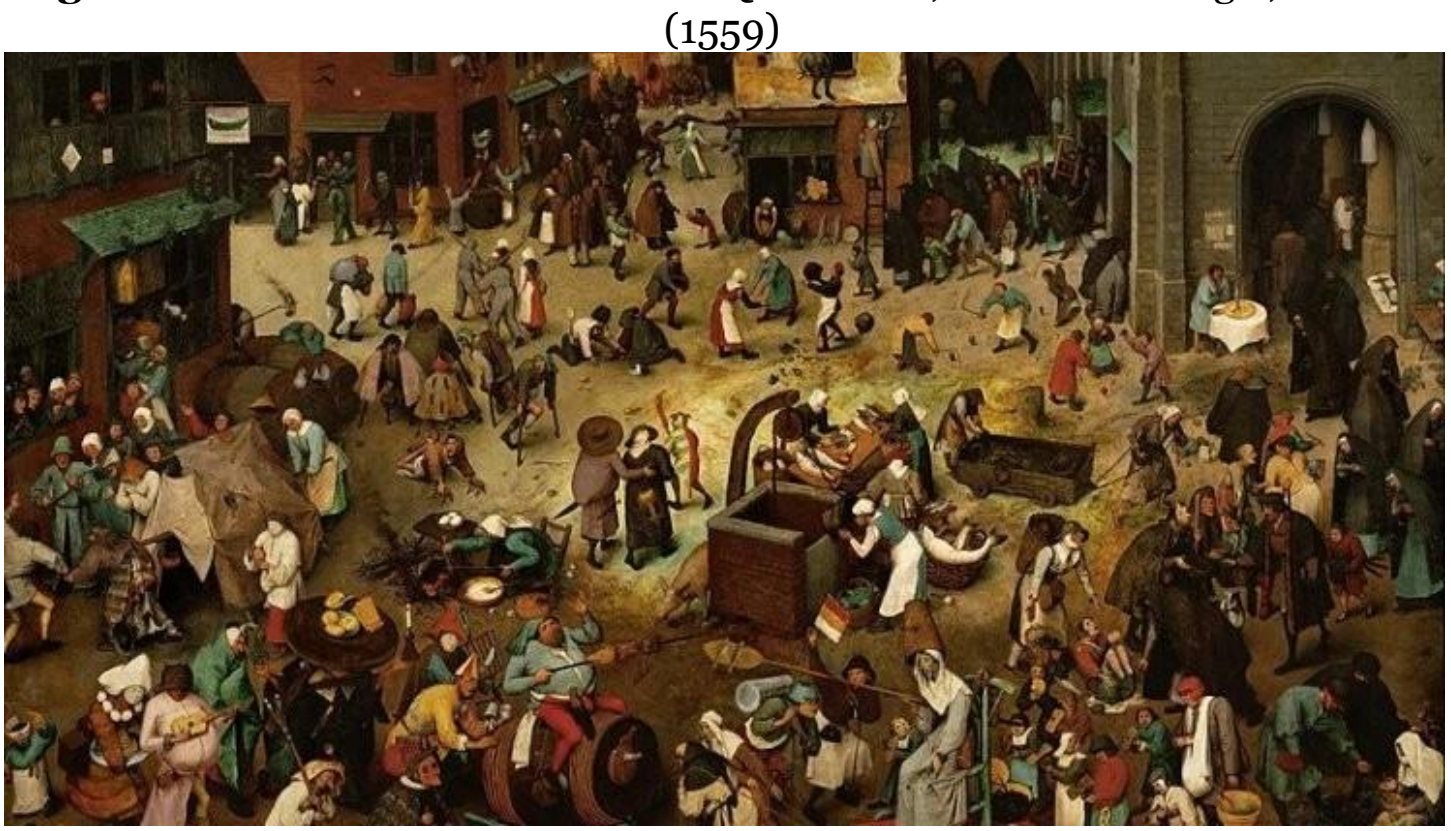

Fonte: BRUNS (2018).

É sugestivo notar que tendo em vista que o conflito de natureza sociocultural, na escala local também é inerente à festa,pois aí também afloram as contradições observadas nas sociedades humanas (sobretudo, capitalistas)verifica-se que, na análise do processo de nacionalização do Carnaval depara-se com um embate travado entre agentes externos(regionais, nacionais)e locais, ao longo de um processo contraditório de reconfiguração da festa. E note-se que esses dois tipos de agentes podem ser respectivamente determinados como aqueles associados: ao Capital global e às tradições do lugar. Ademais, percebe-se que a tensão entre essas duas forças, que Santos (2003) chamou de verticalidades e horizontalidades, resulta num terceiro produto, que não corresponde diretamente nem a um nem a outro, mas sim a uma combinação entre esses dois vetores. E é dessa maneira que é gestado um carnaval em que coexistem características marcantes do local, mas, em que a dinâmica global também se manifesta à sua forma; e ela ocorre e incide, principalmente,nas esferas do consumo e do comércio.Investigando o carnaval do Rio de Janeiro, Frydberg e Eiras (2014) diagnosticaram, aliás, grande crescimento do comércio a ele relacionado, juntamente com o processo de revitalização dos blocos de rua, no início do século. 
O período de fortalecimento dos blocos de rua aponta também para um fortalecimento do comércio no centro da cidade na época que precede a festa e durante a festa, além da própria movimentação do comércio ambulante, oficial ou não. $\mathrm{O}$ comércio urbano passa a fornecer os mais diversos materiais e objetos que servem a brincadeira de rua. Desde objetos como confetes, serpentinas, entre outros, até materiais primários para confecção de fantasias das mais diversas possíveis e materiais para decorações das ruas e ornamentação dos próprios blocos (FRYDBERG, EIRAS, 2014, p. $5)$.

A partir da percepção das autoras é possível, aliás, se constatar que, num cenário de mutação, a dinamização das atividades do Carnaval estaria associada a um sensível crescimento do mercado. Elas pontuam, bastante pertinentemente, que:

Podemos observar então que através do processo histórico do carnaval carioca [...] práticas comerciais e mercantis sempre estiveram presentes na esfera da festa, o movimento que atualmente vem se estabelecendo contudo se diferencia, a festa deixa de abrigar produtos para se tornar o próprio produto mercantil. (FRYDBERG, EIRAS, 2014, p. 6).

E observa-se que quando tal processo se consolida, é que fundamentalmente pode-se notar a apropriação da festa pelo Capital. E é nesse processo de "atualização" e descaracterização, nota-se que componentes locais da festividade perdem o seu valor e se passa, paulatinamente, a se valorizar figuras externas, que inicialmente, não tinham forte ligação com o evento.

\section{OLIVEIRA E SEU CARNAVAL: O LUGAR FESTIVO}

Oliveira é um município localizado a $150 \mathrm{~km}$ a sudoeste de Belo Horizonte (figura 2). Sua história começa por volta da metade do século XVIII, quando colonizadores pousavam em suas terras, nas longas caminhadas empreendidas na "Picada de Goiás"'. A cidade tinha muita importância política e exerceu significativa hegemonia regional no período imperial. Com cerca de

\footnotetext{
6 Antes da chegada dos conquistadores europeus à região, ela deve ter sido ocupada por indígenas da nação cataguá, dizimada pela bandeira de Lourenço Castanho Taques (1662) e, hoje, extinta (DEUS, 2010). O chamado Caminho de Goiás ou Picada de Goiás foi uma das "Estradas Reais" surgidas no Brasil em função do Ciclo da Mineração, no século XVIII. Foi aberta em função da descoberta de ouro aluvionar, no sertão de Goiás.
} 
40 mil habitantes, o município data de 1839, tendo se transformado em cidade a partir de 1861. Com seus quase 160 anos de história, a cidade é dotada de belos casarões antigos, duas lindas igrejas barrocas (figura 3) e uma catedral tombadas como patrimônio histórico.

Figura 2- Localização do município e da sede de Oliveira

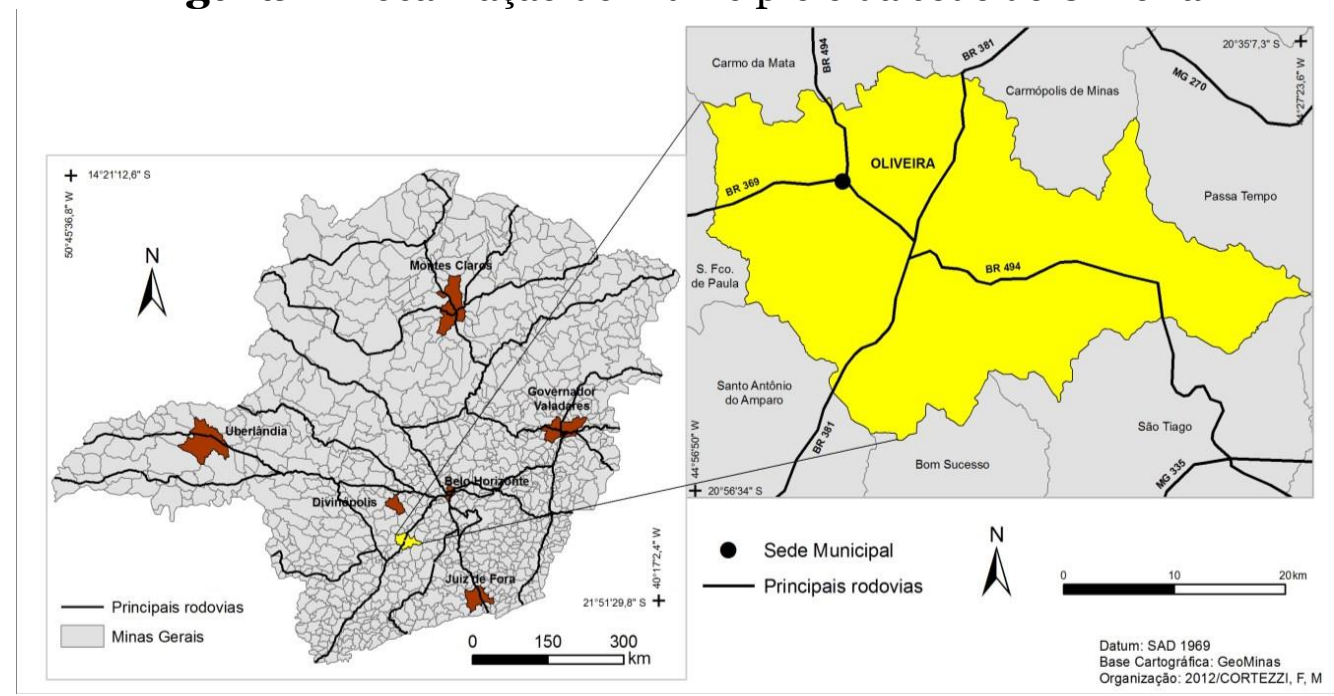

Fonte: CORTEZZI, AMORIM FILHO (2012).

Figura 3- Igreja Matriz de N. S. de Oliveira, na Praça XV de Novembro

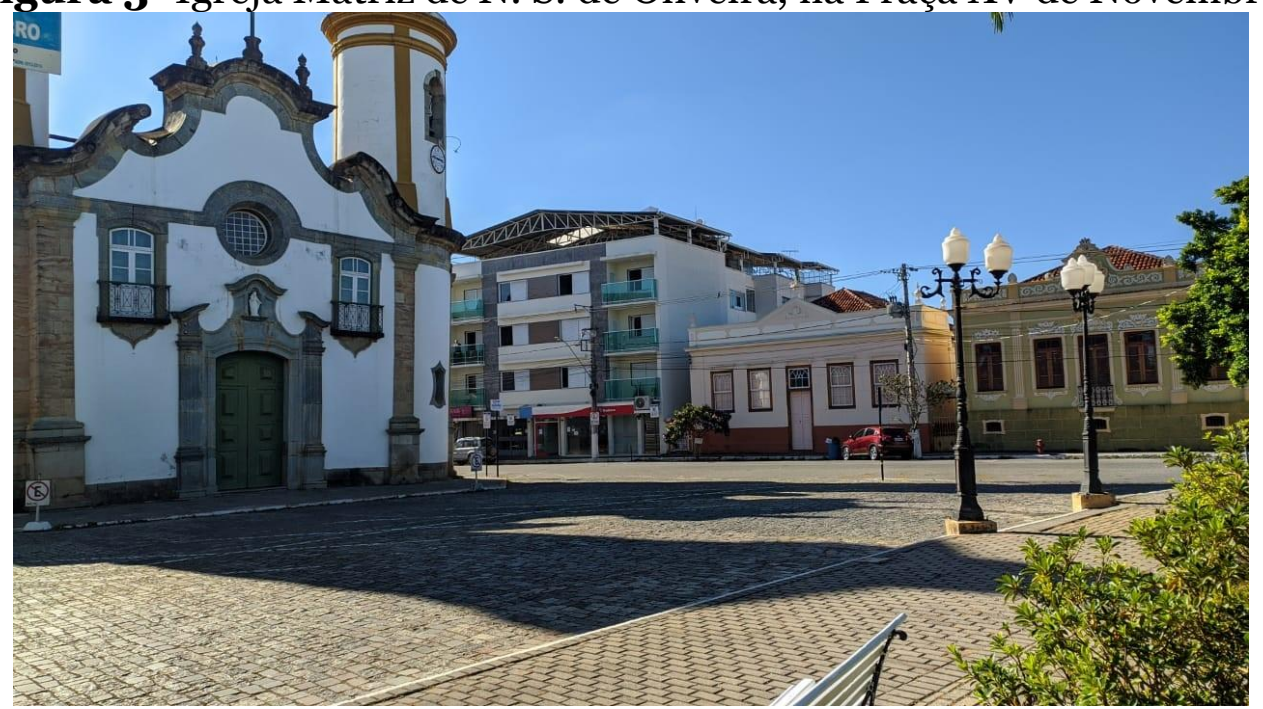

Foto: Arquivo Pessoal.

Por conta de sua extensa biografia, Oliveira conta com rica cultura local, calcada na tradição advinda dos fundadores do lugar e negros escravizados. Os principais marcos dessa cultura são observados em três momentos festivos da cidade: o Congado, a Semana Santa e, o que mais importa neste artigo, o 
Carnaval. Os três eventos são muito marcantes para a cidade e, cada um à sua maneira e em sua época de realização, transforma radicalmente os modos de vida locais, estando extremamente carregados de significados para a população domiciliada na cidade.Todos eles têm como palco principal a Praça XV de Novembro (figura 4), situada na área central da cidade, onde acontecem as celebrações e comemorações mais relevantes para tais festas.

Figura 4- Folder Carnaval 2006/2007, com o mapa do circuito do carnaval da cidade, ao redor da Praça XV de Novembro

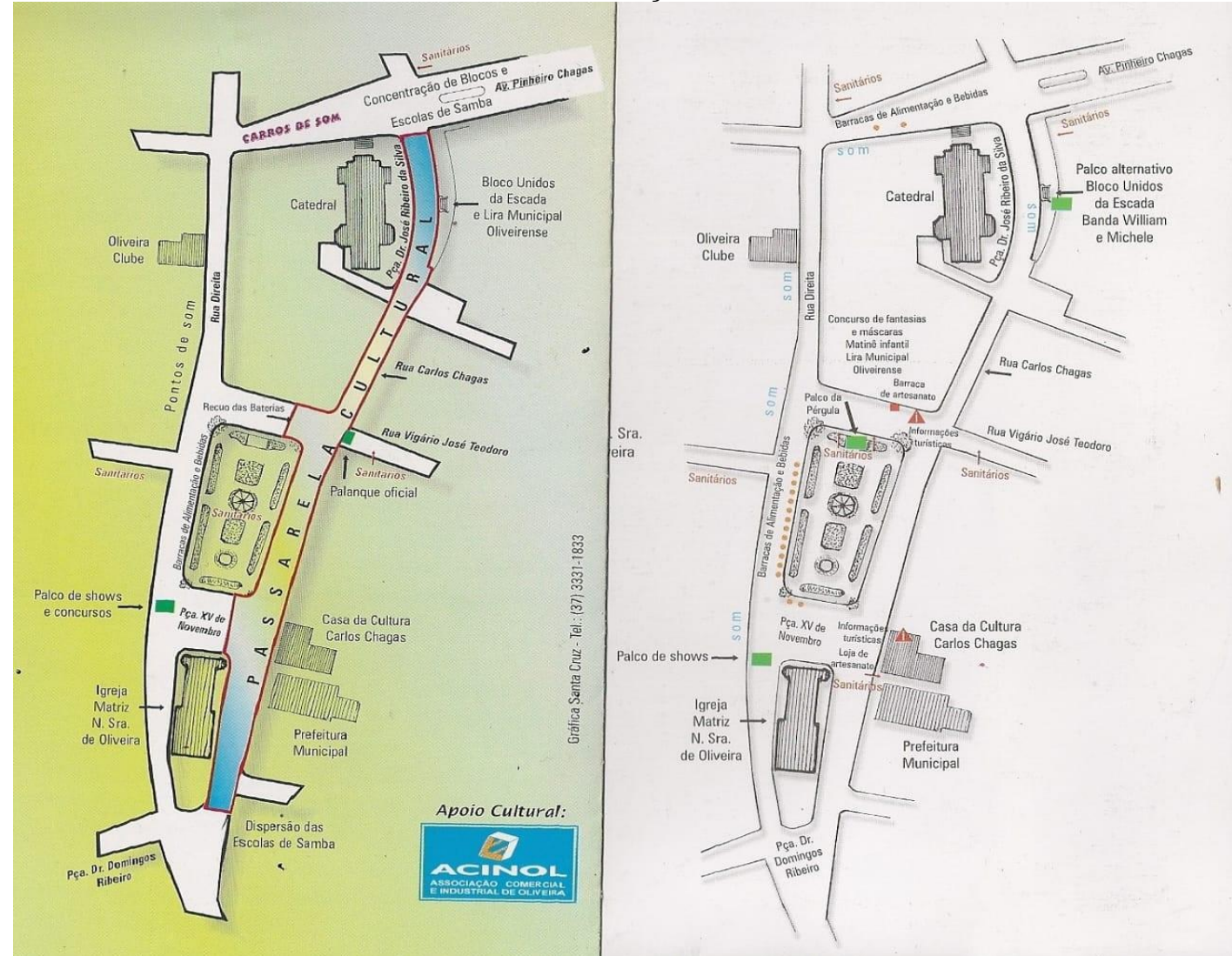

Fonte: Arquivo pessoal de Heraldo Laranjo, criador da imagem, arquiteto, ex-secretário municipal de Cultura de Oliveira.

O carnaval local é amplamente conhecido pelos mineiros, o que é indicado pelo considerável afluxo de turistas de outras cidades mineiras ao evento. Dois blocos são extremamente característicos da festividade: o "Pelo Amooor de Deus" e o "Bloco dos Cai n'Águas". Os dois desfilam, respectivamente, na sexta e quinta-feira de carnaval. O primeiro se resume a pessoas fantasiadas que desfilam dentro do circuito carnavalesco da cidade, na Praça XV, acompanhados pela bateria do bloco. Já o segundo, conta com a participação da figura mais emblemática do carnaval 
oliveirense, o Cai n'Água (figura 5), que é um personagem mascarado que utiliza uma roupa colorida, na maioria das vezes feita de cetim ou chita, conhecida como dominó, com uma espécie de cone na cabeça.

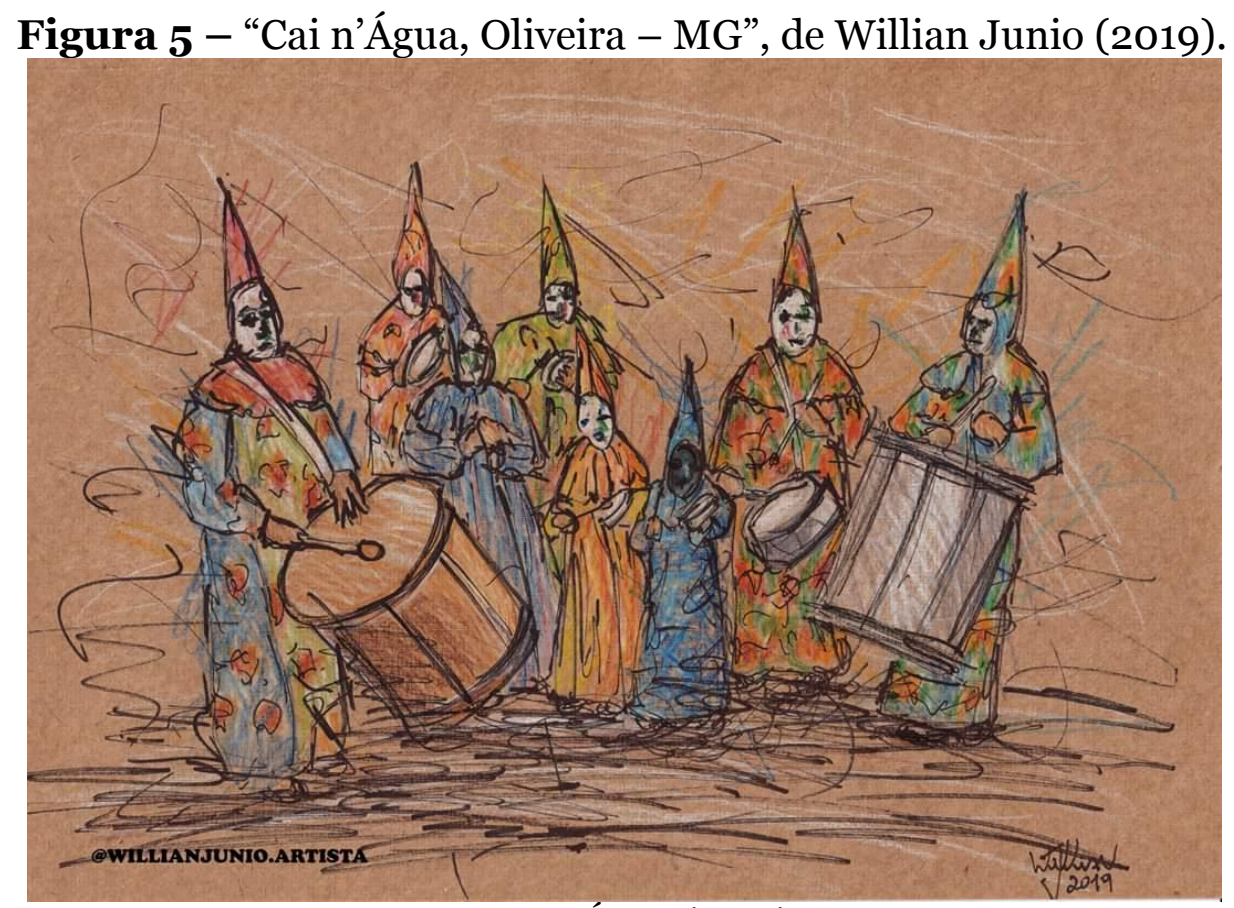

Fonte: JÚNIO (2020).

Por conta, principalmente, dessa peculiaridade do carnaval de Oliveira, a festa mostra-se capaz de aglutinar grande número de foliões, o que faz com que grande parte do setor de comércio e hotelaria da cidade baseie uma parte considerável de sua demanda na festa como temos verificado em interlocuções informais que há tempos temos desenvolvido com os atores aí envolvidos. No entanto em nossa imersão no lugar (como pesquisadores e moradores atentos à questão), percebemos também nesse processo que a cada ano o número de participantes na festa tem caído drasticamente. Segundo a Diretoria de Turismo, através de pesquisas realizadas e encabeçadas pelo diretor de turismo local,em 2006, 55\% dos turistas da cidade tinham como origem a cidade de Belo Horizonte, enquanto em 2017,os turistas provenientes da capital passaram a corresponder a apenas $8 \%$ do total, o que em dados absolutos não demonstra perda de público, mas demonstra que o percentual do número de visitantes advindos da principal fonte de turistas da festividade caiu de forma vertiginosa. Ao mesmo tempo, mais da metade dos entrevistados de 2006, dessa mesma pesquisa, diziam que a melhor parte do carnaval 
da cidade correspondia aos desfiles (dos blocos citados anteriormente) e à tradição, percentagem que caiu para 41\% em 2017.

\section{OS OLIVEIRENSES, O CARNAVAL E AS MUDANÇAS: O FOLIÃO}

Para melhor conhecer o que acontece com o carnaval de Oliveira foram realizadas aí, pelos autores desse texto, pesquisas de campo, em 2019 (nas quais se adotou uma "atitude fenomenológica", devendo-se pontuar que o autor principal do trabalho é natural de Oliveira); e em abril/ maio de 2020, através de vídeoentrevistas, dialogamos também com alguns moradores locais; dentre eles: foliões, jornalistas, políticos e tendo-se optado por se estabelecer interlocuções com pessoas envolvidas na organização da festa, selecionadas, como sinalizamos antes, utilizando-se o critério do seu envolvimento com a festa(ou seja, privilegiamos a dimensão subjetiva da realidade e escolhemos com interlocutores pessoas que têm uma vivência espacial com o lugar festivo investigado). O objetivo das entrevistas realizadas consistia em, a partir do que seria dito, construir uma concepção do que aqueles que vivenciam a festa considerariam central na materialização do lugar festivo. Como observou Sousa (2011, p. 84):

(...) as narrativas de vida espaciais podem se constituir como um parâmetro interessante para o balizamento de biografias espaciais, onde a constituição de um lugar se torna melhor entendida quando relacionada às vidas que o animam e que por ele são animadas.

E sendo assim, optamos por trazer suas falas ao texto sem grandes alterações de conteúdo e dos seus modos de expressão (coloquialmente explicitados, muitas vezes); e agimos assim para que a comunidade tivesse espaço para se manifestar, à sua forma, explicitando, em depoimentos, sua visão a respeito das mudanças passadas pela festa durante os anos (a qual nos propusemos a analisar crítica e qualitativamente- e ainda que, localizadamente, possa se perceber alguma contradição nas falas destes interlocutores). Pontuamos que não tivemos, portanto, a preocupação central em apresentar e discutir dados quantitativos, mas, sim, em apresentar uma percepção (nossa e dos entrevistados) sobre a festividade. 


\section{Entrevistado A - "Um festeiro", participante assíduo de blocos do carnaval local.}

Morei muito tempo fora, em Belo Horizonte, nos Estados Unidos e na Europa, mas Oliveira sempre esteve no meu coração. E eu sou um festeiro. Sempre gostei de todas as festas [e, aprecio] principalmente, as populares, realizadas na Praça XV, que eu nunca perdi. Minha mãe nunca teve preguiça de levar os quatro filhos [aí]. Sempre [nos] levou e sempre ficou o tempo todo [aí]. Eu "fiquei" o mais festeiro da família, de todos. Desde os 5 anos já saía sozinho, principalmente no Carnaval; [e] desde os 7, me fantasiava de "Cai n’Água"; e já estou com 53. Sempre inventamos nossas fantasias, porque a gente não tinha muito dinheiro pra fazer "as coisas", mas a gente inventava muito. No "Pelo Amooor de Deus" saio desde 83 e nunca mais parei. Mesmo quando morava fora, eu vinha participar do carnaval de Oliveira, nunca deixei [de fazê-lo]. Só [houve] um ano [em] que eu passei [o Carnaval] no Rio de Janeiro. Gostei muito, mas ficava "naquela tristeza", pensando "como será que estava [ou... como será que poderia estar] em Oliveira" [ou... como será que poderia estar]. Eu adoro o Carnaval.

Como uma festa de massa é a que mais agrega gente, e a que mais tem poder de influenciar. Porque aqui participam não só as pessoas de nível mais "baixo", tanto cultural quanto financeiro, mas também as de nível mais elevado. Então é a festa mais democrática possível. Todo mundo vai. Com certeza ele foi esvaziado- a gente vê claramente -, mas o brilho dele não foi apagado.

Eu gosto muito da nossa tradição, principalmente do "Cai n’Água”. Ele nunca deixou de sair! Até diminuiu [desde] há alguns anos atrás, mas agora ele teve uma elevação muito positiva, principalmente esse ano. $O$ desfile foi enorme, devido também às campanhas que as pessoas têm feito. Outra coisa é que o nosso carnaval precisa ser na Praça XV, se não ele não vai ter o mesmo brilho. Com os casarões centenários cercando, aquela paisagem linda com a Igreja Matriz "nos observando" lá do fundo. Isso é indescritível, não tem preço!

Minha parte favorita era o desfile das escolas de samba. [Lembro-me de] quando nos preparávamos com as fantasias, meses antes, curtindo e experimentando! No dia, na concentração, era um clima tão gostoso, e quando 
começavam a soar os tambores e os tamborins, era inexplicável; só quem viveu sabe dizer. Quando a gente estava na avenida era uma satisfação tão grande, que me deixava abastecido de alegria por muito tempo.

O Carnaval mudou demais, não só "pelo público" [ou; em termos de público]; mas também [mudaram] as brincadeiras, a participação. A bebida sempre houve, mas as pessoas não precisavam beber pra brincar. A presença das drogas também aumentou muito, o que é muito ruim. A mudança da estrutura do Carnaval, que hoje é bem melhor, é algo muito positivo. Hoje temos um palco melhor, [realizam-se] shows profissionais, toda uma decoração [é] feita exclusivamente para o Carnaval. A criação da comissão responsável também [constituiu um aspecto positivo desse processo de modificações]. Outra "coisa" é a abertura do Carnaval à noite; [pois é uma festa] que antes [se] encerrava por volta das 10 horas, sobrando só os clubes, que hoje não tem mais... Acho que isso aconteceu porque as pessoas precisavam "de uma maneira de se misturar mais". E o mundo mudou; hoje as pessoas pensam [de forma] diferente!

\section{Entrevistada B-Gestora da área da Cultura, em Oliveira que, em nossa avaliação, teve uma postura atuante, durante sua participação na gestão municipal.}

Fui [gestora] por apenas um ano e meio, e nesse tempo organizei um carnaval, [o] de 2016.

No ano de 2015 tivemos uma situação atípica aqui, quando foi proibido o Carnaval7. Nessa [época, da] proibição eu não era [gestora] e "fiz", [promovi] um carnaval, praticamente sozinha, "sem querer" [praticamente sem ter intenção de fazê-lo]. Porque na quinta-feira, "sendo que nossos dias mais importantes" [de festejos de Carnaval] são quinta e sexta a meu ver, já que temos um carnaval que é essencialmente nosso, eu convidei umas amigas e uns amigos pra [vir à] minha casa, e a gente colocou um "sonzinho" na varanda. Não era [um evento] público, era particular, e [então] eu podia por [a música que eu quisesse pra tocar!]. Aí eu coloquei marchinha, coloquei samba-enredo, botei

\footnotetext{
7 Por conta de uma crise hídrica, o carnaval em Oliveira de 2015 foi cancelado, assim como em outras cidades da região. Ainda assim, alguns blocos foram às ruas (SILVA, 2015).
} 
samba, botei essas músicas de carnaval. Quando eu vi, o pessoal "tava” todo dançando lá na frente, e foi assim [ocorreu...] uma condição inusitada. No dia seguinte eu coloquei também, no dia que seria o "Pelo Amooor de Deus", e quando eles viram que tinha um "sonzinho", o bloco saiu. Foi engraçado porque na hora [em] que [o bloco] saiu, os carros estavam passando; então nós fechamos a rua com sacolinhas e impedimos o trânsito. Sei que o carnaval foi feito dessa forma e foi muito bom, porque só tinha oliveirense e o povo não tava "nem aí", [as pessoas] se divertiram muito.

Em 2016 eu já era [gestora]. Foi quando eu fiz uma comissão de carnaval para as pessoas me contarem (já que eu tinha retornado pra Oliveira há pouco tempo) o que acontecia [o que estava acontecendo...] e o que a gente poderia fazer pra melhorar as condições do carnaval. Eu tive muita preocupação com a sexta-feira, porque é o [dia do desfile do] "Pelo Amooor de Deus", que é um bloco que não tem dono, é da cidade. A cidade inteirinha se veste e vai pro bloco brincar o carnaval; com as nossas figuras tradicionais, como a "Mulinha", o "Moita”, essas “coisas" todas que surgiram. E [com] o Cai n’Água, [acontece] a mesma coisa. Eu tive muita preocupação com isso. Eu acho que o grande problema do nosso carnaval "foi no momento em que eles resolveram" 8 , no lugar de deixar o nosso carnaval do jeito que ele era, ou seja, de dia, com o povo fantasiado desde as 9h da manhã; com o Cai n’Água batendo latinha, colocar vários palcos e colocar "coisas" que não eram carnavalescas, como música sertaneja; foi aí [que aconteceu] a nossa grande perda. Como nosso carnaval era muito bom, começou a vir muita gente de fora. Quando isso começou a ocorrer, [apareceram] essas músicas que não são carnavalescas, e massificou-se o nosso carnaval, [passando ele a ser] como em qualquer cidade que você fosse [em qualquer cidade que você vá]. Isso durou muito pouco tempo, porque aí acabou.

O que nós fizemos em 2016, com pouquíssimo dinheiro, [foi, um carnaval] inteirinho enfeitado, organizado, com 40 pessoas na rua de segurança, com o nosso palquinho... Unificamos o som da praça inteira. Tocava o axé, mas depois [se tocava] meia hora de música de carnaval. Tocava outra música, depois mais meia hora de música de carnaval. Foi feito todo um esforço pro

${ }^{8}$ Aconteceu no momento em que se resolveu... 
pessoal voltar pras ruas durante o dia. Mas isso é com o tempo que a gente consegue que volte [a ser] dessa forma. Não adianta [se tentar fazer isso apenas] uma vez.

Voltei com a Rainha do Carnaval e o Rei Momo, que já não tinha mais. Dei toda a estrutura para o "Pelo Amooor de Deus" na sexta, proibindo os sons de qualquer lugar que não fosse o oficial da prefeitura. Foi a única vez [em] que o bloco deu duas voltas completas no circuito do carnaval. Saíram da Barateira, desceram a antiga prefeitura, entraram na Rua Direita e tornaram a dar a volta toda de novo, prestigiando não o [próprio] bloco [apenas], mas [toda] a nossa cidade. O "Pelotão do Golo", que sai depois, eu avisei pra eles que "ou eles sairiam outro dia" ou teriam a paciência de esperar uma autorização minha pra entrar na praça. Porque ninguém pode atrapalhar o "Pelo Amooor de Deus". Eles só entraram na praça perto de 2 horas da manhã. A cada 20 minutos [se] tocava o hino do "Pelo Amooor de Deus" [e que era ouvido] na praça todinha, até a chegada deles [o entrevistado refere-se aqui aos membros do bloco].

É um trabalho que deveria "ser continuado" [ou melhor; ter continuidade], e a meu ver não foi. Por mais que eles gastem, não dão conta de fazer que o nosso carnaval seja um carnaval especial da forma que é, porque está massificado. Quando você massifica, "você vai a qualquer cidade" e encontra [algo semelhante]; [então] é preferível "eu ir"9 pra um bloquinho de bairro de boteco em Belo Horizonte, porque é muito mais interessante.

\section{Entrevistado C - Gestor de Turismo local}

O Carnaval [de Oliveira], em termos de evento turístico [realizado(s) na cidade], é um dos mais importantes. É aquele que traz a maior quantidade de turistas para a cidade. Oliveira é uma cidade de cunho turístico, mas [a atividade é, aqui] ainda incipiente. A gente está trabalhando; desenvolvendo o turismo aqui. E nós temos um retorno muito grande em termos de turistas durante esse período [de realização do carnaval].

Nós realizamos aqui uma pesquisa de demanda turística, "que"10 eu participei efetivamente de 2004 até 2012, período [em] que eu estive

9Em qualquer cidade que você vá; é preferível que eu vá... ${ }_{10}$ Da qual... 
trabalhando na Prefeitura como secretário e diretor de turismo. Houve um hiato nessa pesquisa de 2013 a 2016. Em 2017 eu retornei e nós continuamos. E o que a gente percebe é que houve algumas diferenças muito interessantes [que podem ser notadas, no período], principalmente no que diz respeito à organização do carnaval, à maneira como as pessoas aproveitam a festa, e principalmente no que diz respeito ao financiamento do evento que, [aliás, para o qual], a cada ano que passa, fica mais difícil utilizar recurso público para [o seu] financiamento. Então acaba que a gente fica dependente de iniciativa privada, de patrocínio, de parcerias mesmo.

O que mais mudou, do ponto de vista do folião, diz respeito à questão do tipo de música. Existe um percentual da população mais jovem que gosta de alguns ritmos que não são típicos de carnaval, como o funk, por exemplo. Mas a gente busca a manutenção da tradição pelo menos no que diz respeito a evitar outros tipos de ritmos não específicos do carnaval. Então a gente utiliza e procura manter as marchinhas, o axé, músicas mais relacionadas ou pelo menos [que se sintonizem ou se incluam] no ritmo de carnaval. Inclusive a gente tem uma orientação das forças de segurança pública para que o funk realmente seja evitado por uma questão mesmo de segurança, não pelo funk em si, mas [é que] "acaba que" a música, misturada com bebida, [envolvendo] a população mais jovem, às vezes, [constituída de indivíduos] um pouco mais imaturos, [tudo isso, junto] pode levar a um tipo de briga. Então a gente procura evitar. E nós temos uma parceria, especificamente no que diz respeito a essa população mais jovem, [e assim] é que todos os anos a gente opta por um espaço específico para os carros de som, que são autorizados pela Polícia Militar e pela Prefeitura, pra congregar a população mais jovem que gosta de um tipo de música mais animada. Mas mesmo assim esses ritmos são restritos a ritmos de carnaval.

“Tirando isso"11", nós temos um perfil também de um turista médio em termos de situação econômica [ou poder aquisitivo]. A gente viu que a maioria dos nossos turistas, pela pesquisa que foi feita, ganha entre um e três salários mínimos. E [que realiza] um gasto entre $\mathrm{R} \$ 51,00$ e $\mathrm{R} \$ 100,00$ por dia. Então esse é o perfil específico do turista. Agora [sobre o perfil] do folião, “tem, [há]

${ }^{11}$ Excluindo-se isso... 
muitos moradores da cidade" que também aproveitam [a] festa. $\mathrm{E}$ a gente busca, enquanto poder público, fazer que essa festa seja acessível também para a população local. Existem alguns destinos turísticos onde [ou, em que] "eles procuram" [ou melhor: procura-se] evitar o turismo de massa, e são destinos mais conhecidos, onde "eles aumentam" [ou melhor: se aumenta] muito o preço dos produtos pra [se] tentar evitar a massificação. Nessa situação a população local costuma ficar prejudicada porque não tem acesso a esses produtos. Então a gente tem uma parceria com a área de alimentação, [em] que a gente faz uma parceria com a Associação dos Barraqueiros aqui da cidade. Nisso a gente consegue alguma influência para que haja uma manutenção de preços, no que diz respeito a essa questão do que é consumido.

Já quanto aos shows musicais, a gente prioriza os artistas locais, até mesmo por essa questão de incentivar a cultura local e também pela questão dos custos. Então a gente faz uma parceria e vê com nossos artistas e músicos se eles podem fazer um preço "mais em conta". Mesmo porque o financiamento é muito difícil, como eu já disse.

A estrutura do carnaval de Oliveira é baseada nos blocos caricatos. Então a gente tem aqui o bloco dos Cai n'Águas, que tem mais de 130 anos de tradição, [e ao longo desse tempo, sempre ocorreu] que eles [é que] abrem o nosso carnaval na quinta feira. O "Pelo Amooor de Deus" na sexta que é extremamente tradicional. E um número imenso de outros blocos. Então quem faz o carnaval de Oliveira é o próprio folião. Mas hoje a gente vê uma dificuldade da própria comunidade de se organizar pra estruturar pra poder sair no carnaval. Mas a Prefeitura auxilia, por meio dos recursos do patrimônio histórico, já que nosso carnaval é registrado como bem imaterial, e foi inclusive aceito pelo IEPHA [Instituto Estadual do Patrimônio Histórico e Artístico de Minas Gerais]. Mas no geral eu não vejo uma mudança grande, com exceção desta, comportamental, por parte do folião.

O número de foliões diminuiu principalmente por causa [da reativação do Carnaval de rua] de Belo Horizonte, temos [ou melhor: tem-se] muita gente de Oliveira indo pra lá, e muitos turistas de lá que deixaram de vir [para cá]. Então a gente optou por diminuir a área do evento [ou melhor: a área destinada a ele...], trazendo o que ficava mais afastado pra mais perto do circuito. Então 
em termos de estrutura, a modificação maior [que ocorreu] foi essa. Mas os blocos, a tradição, os Cai n'Águas que são únicos no mundo e [que são] registrado[s] como bem imaterial [do Patrimônio Cultural local], eu não vejo uma modificação [neles]. A não ser essa, [uma mudança] comportamental, principalmente dos mais jovens [como já foi assinalado antes].

\section{Entrevistada D -Uma foliã- "Suspeita pra falar", expectadora da festividade}

Minha relação com o Carnaval começou, eu acho [numa época em] que eu tinha uns 18 anos. E o carnaval de Oliveira era maravilhoso. [Ainda] É maravilhoso! E na minha juventude eu aproveitei demais. Hoje, não; porque sou casada. Mas, era ótimo! Eu não troco o carnaval de Oliveira por nenhum outro.

Oliveira não tem ponto turístico, então essa festa acaba atraindo muitos turistas pra cá. Do meu ponto de vista, pro comércio é muito bom e pras pessoas conhecerem a nossa cidade. Porque não é uma cidade turística. Só assim mesmo, nesses eventos culturais [é que isso pode acontecer].

$\mathrm{Eu}$, particularmente, amo o Carnaval! Mas acho que esse pessoal mais conservador não dá muita importância [à festa], não gosta muito [dela]. Mas eu sou suspeita pra falar; meu marido e minha filha amam carnaval, ela "me puxou”. Do que eu mais gosto são os blocos, as marchinhas, principalmente nos dias mais tranquilos, quinta, sexta e sábado. Aí a gente pode levar a família e aproveitar.

A nossa cidade era mais pacata, agora já "tá" assim... O próprio ritmo das músicas, o funk tomando conta, então ficou meio dividido. Você vê: não "tá" mais ali na Rua Direita, no centro da Praça XV. "Dividiu[-se]” um pouco o Carnaval. E parece que [ele] "tá" perdendo um pouco essa essência do nosso carnaval, como os Cai n'Águas; agora [é] que "tá” resgatando um pouco. Mas "tá" perdendo... Isso "por conta" da juventude; agora, com essas músicas mais eletrônicas e o funk tomando conta. E seria bom se a gente passasse isso de geração pra geração, essa cultura nossa! Mas [ela] tá [se] perdendo...

\section{Entrevistado E -Jornalista e "oliveirense da gema"}


$\mathrm{Eu}$, desde muito tenra idade, gosto de carnaval mesmo, pra valer! Fui um folião de primeira ordem, e por isso andei estudando um pouquinho e me interessei muito, na minha vida, pela história do carnaval de Oliveira. Principalmente no que diz respeito às manifestações mais genuínas da cidade, que são o Cai n'Água, as gatinhas ${ }^{12}$, os blocos caricatos. E principalmente [me interessa], a origem da festa, "lá nos antigamentes", antes mesmo de termos o Carnaval no Brasil, com o antigo entrudo [antiga denominação da festividade que antecedia a quaresma. Remonta às origens do Carnaval] e tal. Li muito a respeito disso. Então minha relação com o carnaval de Oliveira "vai, [trafega] em dois sentidos": primeiro, que eu gosto muito de carnaval e segundo, que eu sou oliveirense "da gema" e adoro essa cidade. E, aí, "eu tive tudo" pra me aprofundar na festa.

O carnaval de Oliveira; ele é "sanguíneo". Ele "tá" na constituição genética do oliveirense. E [é] por isso que a festa daqui é tão tradicional e tão peculiar. Ela não é igual a nenhuma outra festa de Minas Gerais e do Brasil: vou te falar com sinceridade. E essas características foram evoluindo de uma forma muito original durante todos esses anos. Até que se formou, na gente oliveirense, esse gene mesmo de ter a festa como algo essencial durante o ano. Eu imagino que... Por exemplo, eu não sei como será [a festa] no ano que vem, mas se essa pandemia perdurar e nós não pudermos realizar o Carnaval, vai ser uma coisa muito dolorosa para a sociedade, devido realmente a essa "relação umbilical" que a cidade tem com ela. Então o carnaval de Oliveira não é importante só pelo lado do entretenimento, na verdade, ele tem um lado cultural e sociológico que são muito mais importantes que o entretenimento em si.

É dessa forma que, se você mergulhar um pouquinho na dimensão da festa oliveirense, você verá que as pessoas participam com alma. Elas não participam so[mente] com o corpo. Aquilo ali não é só a festa da carne, não é só o carnaval. Mas é realmente uma "festa de alma" e faz parte da nossa história, da nossa gente e da nossa tradição. E daí nós temos nessa festa uma importância capital dessa manifestação popular. Por isso [é] que eu te falei,

12 Outra figura característica do carnaval local. 
porque a presença cultural do Carnaval, ela é importante, em todos os dias, pra nós aqui. E a gente se identifica nas figuras de Cai n'Água, e em tudo aquilo ali, e temos orgulho disso! E a Cultura, [nós] sabemos perfeitamente disso, é uma das "coisas", [uma das dimensões da realidade], mais importantes na vida humana. E aqui a nossa grande manifestação cultural é realmente um carnaval bem original e bem característico.

Eu percebo mudanças no nosso carnaval, mas não pra [o] mal. Eu sinto que há uma mudança “pra [o] bem”, [pra melhor]. Eu não vejo [não avalio], que a festa esteja diminuindo no sentido cultural dela. Foi até bom que ocorresse uma volta às tradições, que redundou numa diminuição de público. E isso aconteceu porque Belo Horizonte começou a explorar a festa como um evento altamente turístico pra capital. E quanto mais festa lá cresce, menos gente vem pra Oliveira. Antes, metade da população de $\mathrm{BH}$ vinha pra Oliveira; a gente falava isso. E isso foi muito bom pro carnaval de Oliveira, porque nós voltamos às nossas origens. E aí acabou com aquele ajuntamento, aquela "maçaroca" que ficava a Rua Direita, que não tinha nem como [se] "atravessar". Ou seja, você era impedido de ser oliveirense numa hora dessas. Aquilo nos calava profundamente. "Poxa, estão roubando a nossa festa, estão roubando a nossa alma”.

A partir dessas entrevistas, se torna possível traçar uma biografia desse lugar festivo e perceber como a dinâmica da festa foi sendo alterada com o passar do tempo. Vê-se, no geral, um carnaval baseado nos blocos caricatos, que passou por diversas mudanças segundo os entrevistados, positivas, para alguns; e negativas, para outros; mas de qualquer forma, reconfigurando-se, "ressignificando-se", como pontuaram Deus et al. (2016), em artigo em que se discute o Estado da Arte da temática: Territorialidades de Festas Populares, contemplada em Grupo de Trabalho desenvolvido no XI ENANPEGE”13.

\footnotetext{
${ }^{13}$ E, também, Deus \& Silva (2015) e Dias Neto \& Deus (2020) - em pesquisas em que os autores analisam o papel que assume um evento- a "Festa das Águas"-, no processo de interação e inserção de uma comunidade tradicional: os índios Pataxó(s) de Carmésia/ MG na atividade turística (e ademais, em toda a sua dinâmica de inter-relacionamento com a sociedade envolvente).
} 


\section{AS TRANSFORMAÇÕES NO CARNAVAL: POR QUE ACONTECERAM?}

Após a obtenção das falas desses oliveirenses, torna-se necessário refletir sobre os motivos que teriam causado as mudanças às quais eles se referem/se remetem.Nessa perspectiva podemos notar que três grandes eixos de mudanças ocorreram na festa: na festa em si, naquilo que concerne às maneiras de se festejar e gostos festivos; e no lugar festivo, pensado como a cidade em que ele se desenvolve em sua nova relação com a capital do estado; e no que concerne ao folião que, também, já não é mais o mesmo.

No primeiro caso, pode-se notar que o Carnaval em si já não é mais como antigamente, como foi percebido por muitos dos entrevistados que, com certo saudosismo, relembram e saúdam os dias de festa que não voltam mais (embora a festividade ainda mantenha certa "pujança" como se pode observar no depoimento de um dos entrevistados que se refere a um "desfile enorme" que ele ainda presenciou) ou no caso em que os entrevistados mostram o seu estranhamento com o comportamento dos turistas atuais. Isso se reflete, segundo eles, em questões, como o consumo exagerado das bebidas alcoólicas hoje observado, os novos ritmos musicais juvenis, aí introduzidos, como o funk; e os componentes externos à festa que a ela foram incorporados, desde fantasias atípicas, estranhas à cultura local até o formato da festa em si, que antes dava destaque aos blocos e agora se redireciona para um carnaval de shows, no contexto do que alguns entrevistados chamaram de "massificação" (ou talvez pudéssemos nos remeter a uma "espetacularização"14 do evento, como problematizam Deus et al. (2016) em relação a outros eventos, na atualidade.).

Para contextualizar essa discussão, vale lembrar que o funk é um gênero musical que se originou em comunidades afro-americanas no século XX (em meados da década de 60), quando se criou uma nova forma de música rítmica $\mathrm{e}$ dançante, produzida através da mistura de soul, jazz e rhythm and blues.Ele se

\footnotetext{
14 Carvalho (2010, p. 47) define "espetacularização" como "a operação típica da sociedade de massas, em que um evento, em geral de caráter ritual ou artístico, criado para atender a uma necessidade expressiva específica de um grupo e preservado e transmitido através de um circuito próprio, é transformado em espetáculo para consumo de outro grupo, desvinculado da comunidade de origem".
} 
caracteriza por uma música com ritmo dançante, sexy, solto, com frases repetidas. Em Oliveira, “a Polícia Militar proibiu a veiculação de funk e outras músicas que façam qualquer tipo de apologia às drogas e violência" (PREFEITURA DE OLIVEIRA - MG, 2014). E note-se que o funk está proibido na cidade, independentemente do conteúdo das letras das canções, ou seja, ele foi vetado do evento enquanto ritmo.

A questão da música tocada na festa, aliás, parece algo muito relevante, algo que fala muito alto para os entrevistados, organizadores do Carnaval e Prefeitura Municipal. Afinal, desde 2014, o funk está proibido de ser veiculado dentro do circuito do carnaval local, como publicado na página oficial, bem como através de Decreto No 4.166 da Prefeitura de Oliveira, do dia 04 de fevereiro de 2020, onde se determina que "fica expressamente proibida a veiculação do gênero musical funk" na cidade (PREFEITURA DE OLIVEIRAMG, 2014). Ainda assim, muitos se queixam da permanência do gênero na festa, mesmo que expressamente proibido, como se pôde ver. E vale ressaltar, por outro lado, que tal interdição em certa medida significa repelir os jovens da festividade e distanciá-los dela, já que é um ritmo muito apreciado por eles, fazendo com que muitos busquem o carnaval de outros locais, e Belo Horizonte tem sido o principal destino desta parcela mais jovem de foliões.

Além disso, percebe-se uma dicotomia na relação capital/ cidade do interior, observada principalmente na sensível redução do fluxo de turistas para a cidade interiorana de Oliveira após a revitalização do carnaval de rua de Belo Horizonte, presente na percepção de um dos entrevistados que declara, por exemplo que: "quanto mais a festa lá [na capital] cresce, menos gente vem pra Oliveira"- fala com a qual a nossa percepção pessoal converge inteiramente. Pois o que pode ter ocorrido é que, a partir de então, as duas localidades passam a competir entre si, tentando, cada uma delas, tornar sua festa carnavalesca mais atrativa para os foliões que a das cidades concorrentes. Vainer(2000) chama, aliás, de cidade-empresa essa cidade gerida estrategicamente e que usa todos os seus recursos, infra-estrutura, etc., para competir por mais investimentos, assim como faz uma empresa. Esta é uma reflexão sugestiva que pode tangenciar o que se passa nos carnavais mineiros (metropolitano e interiorano), 
embora não estejamos postulando, categórica e explicitamente, que tal raciocínio se aplique, de forma direta, aos casos de Oliveira e Belo Horizonte.

Pensando-se nos diferentes atributos e comparando as capacidades desses dois lugares (ou recortes territoriais): Belo Horizonte e Oliveira, pode-se prever que a cidade menor não tem qualquer chance de superar a maior em termos dos equipamentos disponibilizados aos turistas. Afinal, os setores de hotelaria, serviços, alimentação e outros são muito mais desenvolvidos na capital, sobrando para a cidade do interior somente o trunfo da peculiaridade da sua festa e a tradição. Para a maioria dos jovens, no entanto, essas duas características do evento festivo pouco importam; e vai se observar que é gigantesco o contingente de visitantes que a capital consegue receber-e de fato, recebe-, nos dias de folia, demonstrando quão atrativo seu carnaval se tornou para este público mais jovem. Tanto é assim que Belo Horizonte que era uma cidade que, até a alguns anos ficava semi-deserta no Carnaval (com a evasão de parcela dos seus habitantes para cidades litorâneas ou interioranas), hoje vive um frenesi no Carnaval com levas de foliões presentes nas ruas atrás dos blocos, interdição de vias para usufruto destes foliões, etc.- experiência claramente vivenciada- acreditamos!- pela maioria dos seus cidadãos. Vale ressaltar, nesse sentido, depoimentos dos entrevistados lastimando a presença (e interferência!), no carnaval oliveirense, dessas "músicas mais eletrônicas... e o funk tomando conta".

Quando o folião assume centralidade na discussão é necessário, por outro lado, se pensar nas preferências do indivíduo. $\mathrm{E}$ ao analisarmos mais especificamente o perfil dos foliões que correspondem aos turistas contemporâneos, percebemos que se trataria de um ator que tende a se vincular menos a uma determinada cultura, o que pode condicionar um comportamento de abandono das tradições por tal segmento de foliões (como se observa na valorização, por estes outsiders, de um ritmo exógeno ao Carnaval tradicional como o funk), consequentemente, fragilizando-as ou levando-as à decadência, o que para as cidades para as quais tal caráter tradicional constitui o principal atrativo de suas festividades, pode significar um grande problema, um impasse... 


\section{CONSIDERAÇÕES FINAIS}

Observou-se ao longo da problematização aqui desenvolvida sobre o tema das festas populares, focalizando-se o caso da festa carnavalesca oliveirense, que é muito fecunda a abordagem da questão, na ótica das investigações e práticas geográficas (sobretudo no que concerne aos estudos culturais). Este é um dos enfoques que propicia que, em festas como o Carnaval, existe a possibilidade de reinvenção do novo, uma vez que se observa que tais eventos têm, objetivamente, a capacidade de se transformar, diante dos novos enredos sociais que emergem e aos quais eles se imbricam e se interdigitam (DEUS et al., 2016), num quadro de sucessivos realinhamentos e contradições que os marca a exemplo das mudanças vivenciadas no Carnaval de Oliveira, com a introdução de novos hábitos e comportamentos "modernos" (exacerbação do consumo de álcool, ligação dos foliões com o funk, "espetacularização" da festa...).

Consideramos, como sujeitos imersos no universo da pesquisa (e autores do trabalho), que, embora as mudanças na festa sejam explícitas e, consequentemente, percebidas e observadas por todos os entrevistados, o simbolismo do Carnaval e seu papel enquanto construtor da identidade do oliveirense permanece como algo muito forte. Por isso, a forma das pessoas se remeterem a ele é muito respeitosa, "reverente", até "efusiva", com falas carregadas de sentimentos de afinidade e pertencimento. Aliás, esses fatores é que definem o objeto de estudo como um lugar, pensado enquanto "qualquer localidade que tem significado para uma pessoa ou um grupo de pessoas" (TUAN, 2011, p. 5).Consequentemente se torna necessária uma análise crítica do que é dito, já que muitas vezes os depoimentos colhidos têm um caráter muito mais emotivo do que "técnico", frequentemente mostrando-se contraditórios entre si. Assim, há uma tentativa de enfatizar um carnaval que sempre foi maravilhoso e tradicional, quando na realidade existe uma festividade em constante transformação, que não tem sequer origem nacional, como tratado no início deste artigo.

Uma questão a ser notada é que os entrevistados, no geral, demonstram certo temor do que eles chamam de massificação do carnaval, que aqui relacionamos a uma espetacularização da festividade. Alguns autores observam 
esse movimento em algumas manifestações de culturas populares, como Trigueiro (2005). E o autor observa um elemento semelhante ao que propomos quando descrevemos o carnaval, no qual as duas forças de chocam - local e global -, e um terceiro, surge. Assim, a própria disputa modifica a festa, já não sendo ela a mesma que antes.

Outra questão que precisa de ponderações é a criminalização do funk no carnaval oliveirense. Como bem pontuam Luvizotto e Zanetti (2020, p. 49) "a estética do Funk, gênero que tem origem a partir de uma classe marginalizada e moradora das periferias, é frequentemente associada à criminalidade e a violência”, argumento utilizado por muitos, inclusive pela Prefeitura Municipal e a Polícia Militar, para proibi-lo na cidade. Fica nítido, aí, o caráter pouco fidedigno do estabelecimento apriorístico dessa relação já que, apesar do tempo de proibição do gênero, deve se pontuar que ainda se faz, preconceituosamente, uma conexão entre ele eo uso de drogas, violência e criminalidade no geral que existem na festa; então se pode questionar se a interdição do funk tem uma relação exclusiva com o seu caráter de ritmo estranho à cultura tradicional local ou se ele foi "banido" devido à sua natureza "heterodoxa".

Destaca-se, por fim, a excepcionalidade da sucessão de transformações experienciadas pelo lugar-festivo de Oliveira, com suas peculiaridades, enquanto acreditamos que ocorra, simultaneamente, um movimento genérico, na mesma direção, nas cidades carnavalescas tradicionais do interior mineiro, atrelado a uma disputa intensa, que se manifesta aí, pela hegemonia simbólica, numa atmosfera de símbolos que se adensa durante o período de realização da festividade.

\section{REFERÊNCIAS}

ALMEIDA, M. G. A produção do ser e do lugar turístico. In: SILVA, J. B.; LIMA, L.C; ELIAS, D. Panorama da Geografia Brasileira I. São Paulo: Annablume/ANPEGE, 2006, p. 109-122.

BRUNS, G. Luta entre o carnaval e a quaresma. 14 fev. 2018.Linkedin: usuário do Linkedin. Disponível em: <https://pt.linkedin.com/pulse/lutaentre-o-carnaval-e-quaresma-guilherme-lacerda-bruns $>$. Acesso em 22 jun. 2020. 
CARVALHO, J. J. 'Espetacularização’ e ‘canibalização’ das culturas populares na América Latina. Revista ANTHROPOlógicas, Porto (Portugal), v. 21, n. 01, p. 39-76, 2010.

CORTEZZI, F. M.; AMORIM FILHO, O. B. Oliveira-MG: uma "Cidade Média" na Zona Perimetropolitana de Belo Horizonte? Caderno de Geografia, v. 22, n. 38, p. 35-53, 2012.

DA MATTA, R. Carnavais malandros e heróis- para uma sociologia do dilema brasileiro. 3. ed. Rio de Janeiro: Zahar, 1981.

\section{DEUS, J. A. S. Geografia Cultural do Brasil/ Etnogeografia. Belo} Horizonte: Editora UFMG, 2010.

DEUS, J. A. S. et al. Territorialidades de festas populares: Espaço/ Tempo cognitivo, conectivo e conflitivo. Revista ANPEGE, v. 12, n. 18 (no. especial GTs/ XI ENANPEGE), p. 347-362, 2006.

DEUS, J. A. S.; SILVA, L. R. M. Reinvenção da identidade cultural, protagonismo etnopolítico e interações com o turismo dos índios Pataxó(s) de Carmésia (estado de Minas Gerais, Brasil). Agália, Santiago de Compostela (Galiza), no. especial (Turismo em Terras Indígenas), p. 203-223, out. 2015.

DIAS NETO, J.; DEUS, J. A. S. O Mapa Mental como ferramenta de análise sobre o Lugar: a percepção da comunidade pataxó da Terra Indígena Fazenda Guarani pela sociedade envolvente de Carmésia/ MG. In: REGO, Nelson, KOZEL, Salete. Narrativas, Geografias, Cartografias- Volume I. Porto Alegre: Editora Compasso Lugar- Cultura e Editora IGEO, 2020, p. 127-154.

FERREIRA, L. F. O lugar festivo: a festa como essência espaço-temporal do lugar. Espaço e Cultura, Rio de Janeiro, v. 15, p. 7-21, 2003.

FRYDBERG, M. B.; EIRAS, R. E. C. Eu quero é botar meu bloco na rua: o Carnaval dos Blocos no Rio de Janeiro entre a mercantilização e as práticas tradicionais. In: Encontro Nacional de Estudos do Consumo, 7., 2014, Rio de Janeiro. Anais [...] Rio de Janeiro: Grupo de Estudos de Consumo, 2014, p. 0114 .

G1. Carnaval 2018 deve injetar R \$ 11 bilhões na economia, diz Ministério do Turismo. G1, Belo Horizonte,25 jan.2018. Disponível em:

<https://g1.globo.com/ carnaval/2018/noticia/carnaval-2018-deve-injetar-r-11-bilhoes-na-economiadiz-ministerio-do-turismo.ghtml>. Acesso em: 25 jun. 2020.

GERMANO, I. G. O Carnaval no Brasil: da origem europeia à festa nacional. Caravelle, Toulouse, v. 73, p. 131-145, 1999.

JUNIO, Willian. Desenho com lápis de cor e caneta permanente. 22 abril 2020. Instagram: @willianjunio.artista. Disponível em: 
<https://www.instagram.com/p/B_SKsQxgfXO/?igshid=knl5soaohjxv>. Acesso em: 27 ago. 2020

KOZEL, S. Mapas Mentais: dialogismo e representações. Curitiba: Appris Editora, 2018.

LUVIZOTTO, Caroline Kraus; ZANETTI, Lucas Arantes. O sensível como agente da esfera pública: o uso da razão e emoção no debate online sobre a proposta de proibição do Funk. Revista ComHumanitas, v. 11, n. 1, p. 37-53, 2020.

MATIAS, R. Crise e concorrência com BH levam mais de 200 prefeituras mineiras a cancelar o Carnaval. Hoje em Dia, Belo Horizonte,14 fev. 2019. Disponível em: <https://www.hojeemdia.com.br/primeiro-plano/crise-econcorr\%C3\%AAncia-com-bh-levam-mais-de-200-prefeituras-mineiras-acancelar-o-carnaval-1.693755>. Acesso em 25 jun. 2020.

\section{PREFEITURA DE OLIVEIRA-MG. Prefeitura de Oliveira confirma}

Carnaval 2014. Oliveira, 20 fev. 2014. Facebook. Disponível em:

<https://www.facebook.com/permalink.php?story_fbid=653478324708767\&id $=472026389520629>$. Acesso em 22 jun. 2020 .

SANTOS, M. Por uma outra globalização: do pensamento único à consciência universal. 10. ed. Rio de Janeiro: Record, 2003.

SILVA, A. L. Mesmo com carnaval cancelado, blocos vão às ruas em Oliveira. G1, 14 de fev. de 2015. Disponível em: <http://g1.globo.com/mg/centrooeste/noticia/2015/o2/mesmo-com-carnaval-cancelado-blocos-vao-ruas-emoliveira.html>. Acesso em: 27 ago. 2020.

SOUSA, P. P. A. As geo-grafias da memória: o lugar festivo como biografia espacial. Ra'ega, Curitiba, v. 20, p. 81-93, 2011.

TRIGUEIRO, O.M. A espetacularização das culturas populares ou produtos culturais folkmidiáticos. Revista Internacional de Folkcomunicação, v. 1, n. 5, p. 1-9, 2005 .

TUAN, Y. Espaço, Tempo, Lugar: um arcabouço humanista. Geograficidade, Niterói (RJ), v. 01, n. 01, p. 4-15, Inverno 2011.

VAINER, C. Pátria, empresa e mercadoria: notas sobre a estratégia discursiva do Planejamento Estratégico Urbano. In: ARANTES, MARICATO, VAINER. A cidade do pensamento único. Petrópolis: Vozes, 2000, p. 75-104. 